\title{
STRESS ANALYSIS AND TOPOLOGY OPTIMIZATION OF A CHAIN BUCKET ELEVATOR USING ANSYS
}

\author{
Edward Yin*, Emmanuel M. Seckley, Evans Kesse Asiedu, \\ Stephen Cobbinah
}

\author{
University of Mines and Technology, Faculty of Engineering, Department of Mechanical Engineering, P.O. \\ Box 237, Tarkwa, Ghana \\ * corresponding author: eyin@umat.edu.gh
}

\begin{abstract}
A failure of conveyor chain links in a production process can cause unscheduled shutdowns, which increase the throughput time coupled with damaged buckets and chain links, which increase maintenance and repair costs. Since failures of conveyor chains are inevitable, this research aims to modify the design of the chain bucket elevator by incorporating a ratchet mechanism, which will prevent the chain bucket assembly from dropping to the bottom of the chain bucket elevator whenever there is a chain-link failure and also avoid the jamming of the bucket chain assembly against one another when dropping to the bottom of the elevator during failure. The number of damaged buckets and chains will be minimal, thereby reducing the maintenance and repair costs. Also, the time required for replacing the failed chain link will be reduced, which in turn, will reduce the down-time, thereby increasing the production rate. The ratchet mechanism, which can withstand a maximum load of $38.10 \mathrm{kN}$, comprises a toothed wheel, a pawl, and a spring. An analytical method was employed for the initial analysis and the results were verified using the FEM. Topology Optimization was carried out on the beam and lever with results showing a $20 \%$ and $26 \%$ weight reduction from the original, respectively. The stresses induced in the beam and lever increased significantly by $36 \%$ and $47 \%$, respectively, because of the optimization, however, they remained within the acceptable limits.
\end{abstract}

KEYwords: Stress analysis, bucket elevator, conveyor chain links, optimization, finite element method.

\section{INTRODUCTION}

The FE based design optimization (DO) is a welldeveloped and established method for determining design parameters that lead to the best measurable performance (optimal solution) of a mechanical structure, device, or system under given constraints. As a result, there is a rising demand for lower production cost, more efficient, less expensive and innovative methods to improve the performance of the existing systems. Optimization can be used to solve different engineering problems, including design of aircraft and aerospace structures aiming for minimum weight, vibration and noise optimization of automobiles for ride comfort, optimal design of electrical networks, analysis of statistical data and building empirical models from experimental results to obtain the most accurate representation of the physical phenomenon as well as optimal production planning, controlling and scheduling.

Depending on the type of design variables, the finite element-based optimization may be classified as a parameter or size, shape and topology optimization. While shape and size optimizations are quite well known, the topology optimization is beginning to gain its importance in commercial optimization codes. The topology optimization generates the optimal shape of a mechanical structure as shown in Fig. 1. In this study, the topology optimization will be employed to optimize the components of the modified bucket elevator.

In the topological optimization, the objective function $(f)$ is a subject that is minimized or maximized to the defined constraints $\left(g_{j}\right)$. The density of each finite element $(i)$ is treated as a design variable $\left(\eta_{i}\right)$ in the topological problem. The pseudo density for each element varies from 0 to 1 ; where $\eta_{i} \approx 0$ represents material to be removed; and $\eta_{i} \approx 1$ represents material that should be kept. Mathematically, the optimization problem is expressed as:

$$
F=\text { minimize or maximize w.r. to } \eta_{i}
$$

Subjected to $\leq \eta_{i} \leq 1$ where $i=1,2,3 \ldots N$

$$
g_{j l}<g_{j}<g_{j u} \text { where } j=1,2,3 \ldots M
$$

Where

$N=$ number of finite elements

$M=$ number of constraints

$g_{j}=$ computed $j^{\text {th }}$ constraint value

$g_{j l}=$ lower bound for $j^{\text {th }}$ constraint

$g_{j u}=$ upper bound for $j^{t h}$ constraint

Central chain bucket elevators are basically designed to move granular materials vertically through a height. The elevators use an endless chain with a series of buckets attached to it. The bulk material is spread into an inlet hopper where the buckets dig into the material and convey it up over the head sprocket. Thereafter, the buckets throw the material out via 


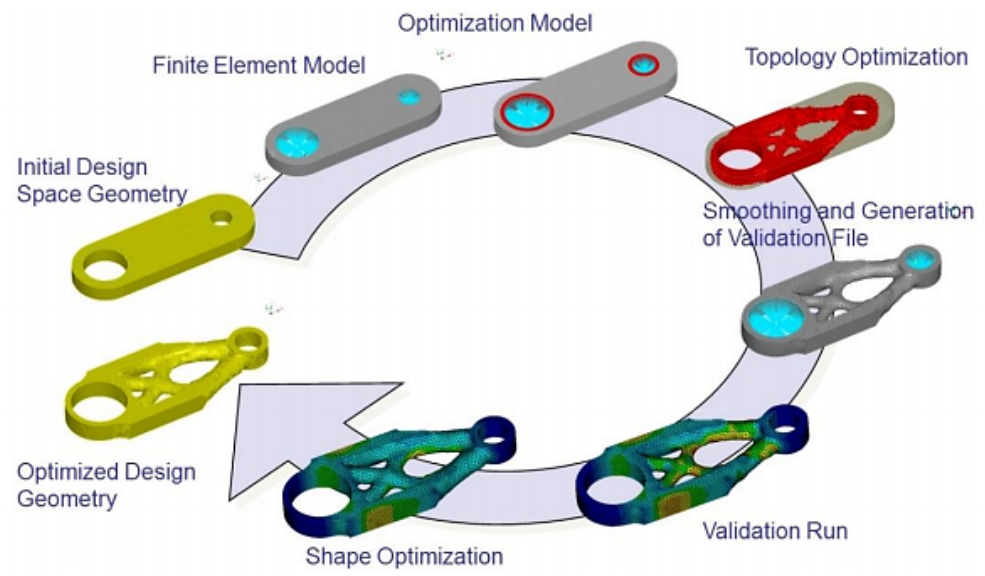

Figure 1. Topology Optimization Process [1].

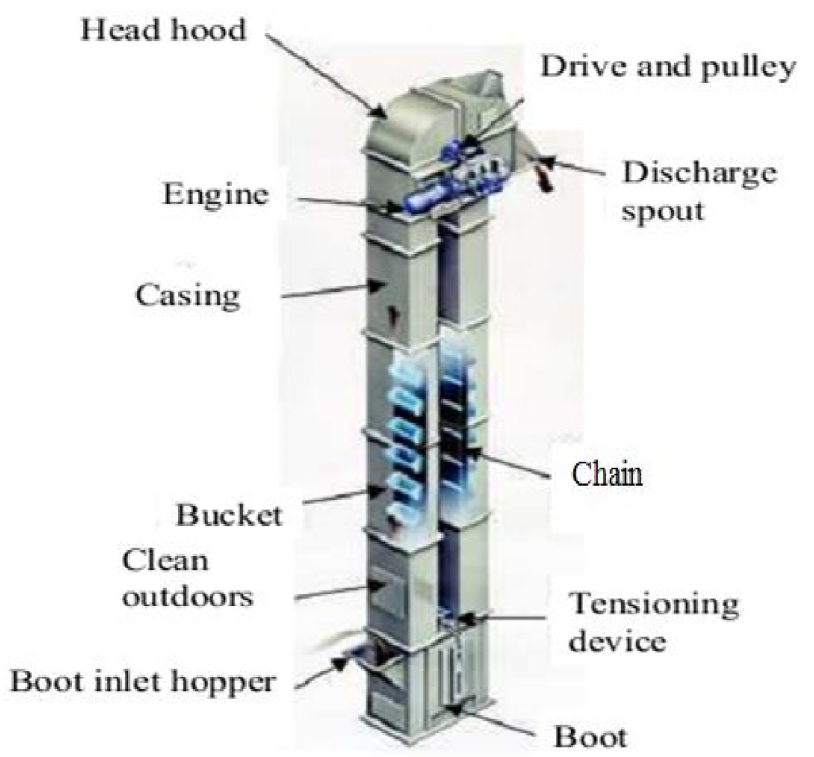

Figure 2. Parts of a Bucket Elevator [3].

a discharge spout. The buckets are returned down to the tail sprocket at the bottom and the cycle is repeated..

The bucket elevator consists of buckets to contain the material, chain/belt drive to carry the buckets and transmit the pull. In addition, it also has an electrical motor to drive the chain or belt, loading and discharge spout for loading the buckets at the boot and receiving the discharged material at the head, respectively. A tensioning device is also installed for maintaining the chain/belt tension. All these accessories are enclosed and protected in a casing 2]. Fig 2 shows the various parts of the bucket elevator.

The buckets are designed to stay upright after scooping the material to prevent spillage. The head is one of the major structural elements of the overall elevator. It supports the weight of the buckets and belt and accommodates the drive and anti-run back device [4.

Bucket elevators are the most efficient means of elevating free-flowing granular materials and even some sticky materials. Bucket elevators offer a practical, efficient, and economical means of elevating a wide variety of dry, free-flowing bulk materials vertically [5]. The bucket elevators are employed in various applications and are the ideal solution where products need to be elevated and only consume a small ground area 6. They are employed in the lime, cement, and grain industry for conveying fertilizers, powders, grains, minerals, salt, potash and in the building industry for conveying stones and mortar. They are also suitable for transporting hot materials (up to $1000^{\circ} \mathrm{C}$ ). For free-flowing bulk materials, which need to be conveyed vertically, bucket elevators are the best option. Conveyed products are mostly granular solids, which range from powders to rocks. Limitations depend on how easily a product can be loaded into and discharged from the bucket. Large granular products are difficult to load while sticky products are difficult to discharge. For products that are fragile and easily crushed, slower conveyance speeds must be used [6].

There are mainly two types of bucket elevators; the belt and chain bucket elevators. The main difference between the two is that the former uses an endless belt with pulley whilst the latter uses an endless chain with a sprocket as shown in Fig 3 a) and b).

Whenever the chain links of the bucket elevator fail, it takes the technicians a minimum of three (3) days to fix it. This is because when one of the chain links fails, all the chains together with the buckets drop to the bottom of the bucket elevator. A chain block is then used to pull the chain link up through a height of between 15 to $25 \mathrm{~m}$ depending on where it failed to join them. In addition to this, some of the links and buckets get damaged and they need to be replaced with new ones. This results in an increased down-time and severely affect the production time. Moreover, since the damaged buckets and links need to be replaced with new ones, the maintenance cost is increased. In view of this; the research aims to address this problem by introducing a ratchet mechanism, which will hold the chain links and buckets in position when there is a failure in order to prevent them from being damaged 


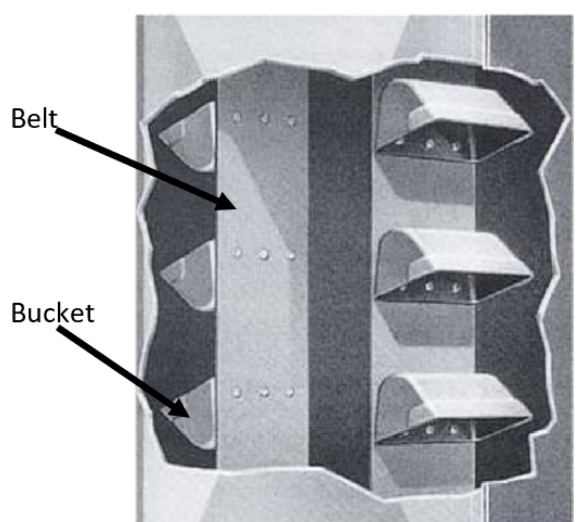

(a)

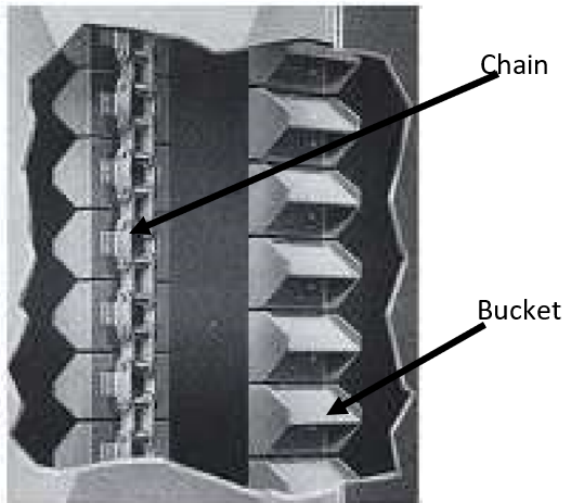

(b)

Figure 3. Chain and Belt Bucket Elevator.
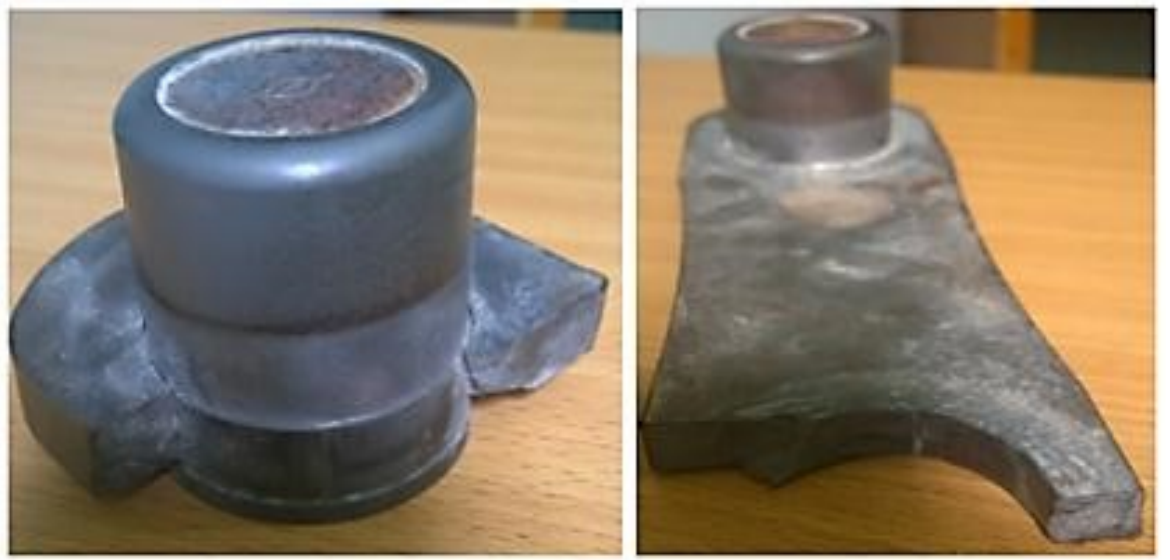

Figure 4. Failed Chain Links [7].

and also address the difficulty in joining the chain links together again.

Bucket elevators are very important to the extent that the whole production process halts whenever the elevator is not in operational condition and this is mostly caused by failure of chain links as shown in Fig. 4 Although other parts such as the bearing, shaft, and gears can also fail, the failure of chain links is much more frequent. Failure of chain links does not only reduce productivity but also the cost of maintenance because of damaged buckets and links associated with the failure. The specifications of the investigated bucket elevator are shown in Table 1 .

The above data were obtained from East African Portland Cement Company (EAPC), Kenya. On the average, the downtown is three (3) days, which in terms of hours is $72 \mathrm{hrs}$. Therefore, the amount of cement lost during the downtime is 5760 tons $(5,760,000 \mathrm{~kg})$, which in terms of bags of cement, is 115,200 bags of cement. It is therefore imperative to analyse and come up with a design that will reduce down-time, which in turn, will increase productivity. Down-time is the number of hours during which the bucket elevator is not in operation. An analytical method was employed in designing the various components of the ratchet mechanism and these results were verified using the FEA. Subsequently, a topology optimization was carried out to obtain an optimal shape of each component. A stress analysis was performed for the stress levels induced in the optimal shape.

\section{LiterATURE REVIEW}

A thorough literature analysis has been carried out to comprehend the subject matter. The literature review mainly focused on various studies on bucket elevators to improve its performance and the failure of the chain links. Various methods of analysing the bucket elevator and obtained results are discussed. Also, failure modes and causes of failure of the chain links are presented.

In their study, Patel et.al. [8] improved the design of a belt bucket elevator by changing the material of the pulley shaft from EN-8 to EN-24. EN-24 had a better fretting corrosion resistance than EN-8. A static structural analysis was performed on the shaft using ANSYS simulation software under standard operating conditions. The performance of the two materials under deformation, safety factor and von Mises stress were compared as shown in Table 2.

It was concluded that the belt bucket elevator failed mainly due to breaking occurring at the inner edge 


\begin{tabular}{llc}
\hline SN & Item & Quantity \\
\hline 1. & Capacity & $80 \mathrm{t} / \mathrm{hr}$ \\
2. & Power Rating & $57 \mathrm{~kW}$ \\
3. & Speed & $1.62 \mathrm{~m} / \mathrm{s}$ \\
4. & Diameter of Sprocket & $0.762 \mathrm{~m}$ \\
5. & Weight of Chain per Unit Length & $57 \mathrm{~kg} / \mathrm{m}$ \\
6. & Height & $30 \mathrm{~m}$ \\
7. & Width & $1.5 \mathrm{~m}$ \\
8. & Average Temperature & $75{ }^{\circ} \mathrm{C}$ \\
\hline
\end{tabular}

TABLE 1. Specification of Bucket Elevator.

\begin{tabular}{lccc}
\hline & Deformation/mm & Von Mises stress/MPa & Safety Factor \\
\hline Existing material EN-8 & 2.2381 & 199.11 & 2.3 \\
New material EN-24 & 1.9412 & 182.02 & 3.0 \\
\hline
\end{tabular}

TABLE 2. Simulation Results.

of the pulley, which is considered as fretting corrosion. From the analysis shown in Table 2, EN-24 was suggested for the shaft as it showed better results for deformation, von Mises stress and safety factor than the existing material, i.e., EN-8.

Using the Finite Element Analysis, Yashaswini et.al. [6] designed and optimized a bucket elevator with a capacity range of $10-20$ tons $/ \mathrm{hr}$. The modelling of the bucket elevator was done using CAD software and, subsequently, the bucket and gear shaft assembly was simulated using ANSYS simulation software under various capacities of 10,15 and 20 tons/hr. The deformation, maximum deflection and factor of safety of the bucket together with that of the gear shaft assembly was determined as shown in Table 3 and Table 4 A modal analysis was also used to determine vibration characteristics of the components.

It was concluded from the simulation results that the static stresses developed in the Bucket Elevator are within the permissible limits. From the Modal analysis, it was observed that the bucket may vibrate violently at a frequency of $170 \mathrm{~Hz}$ during a speed of $1 \mathrm{~m} / \mathrm{sec}$ on the chain drive with a frequency range between $0-300 \mathrm{~Hz}$ whereas the gear shaft undergoes vibrations at a frequency of $1117 \mathrm{~Hz}$. In conclusion, the capacity of the bucket elevator was increased to 20 tones $/$ hr.

In their paper, Taher et.al. 9] designed a combination of a belt conveyor and chain bucket elevator, which is controlled automatically by a micro controller with a weight sensor attached to it for packaging. Prototypes of the belt conveyor and chain conveyor were produced by employing various workshop processes such as metal cutting, soldering, welding, boring, drilling, grinding, facing and turning. The belt conveyor and bucket elevator were then synchronized to perform the function for which they were designed i.e. to automate the handling of bulk material and its packaging. It was concluded that the control system helps packaging the right amount of material in several packets. Once set, the required skill for operating the system is also reduced, as compared to a manual system.

In their paper, Barshi et. al. [10] modelled and analysed a belt bucket elevator using SOLIDWORKS to optimize the weight and discharge capacities of the bucket elevator. The weight reduction was carried out on both the bucket and shaft by changing the bucket material from structural steel to aluminium and shaft material from structural steel to EN-8. The weight of the bucket was reduced from 3.2 to $2 \mathrm{~kg}$, which resulted in a $38.27 \%$ decrement since aluminium is lighter than structural steel, whereas the diameter of the shaft reduced from $187 \mathrm{~mm}$ to $168 \mathrm{~mm}$ since EN-8 material is a stronger material than steel.

In their studies, Deoka et. al. [11] used the FEA and Topology optimization techniques to carry out a weight reduction of the buckets of a bucket elevator. The maximum stress value of the existing buckets was very low, as compared to the allowable stress, and therefore the need for optimization. The topology optimization was used to find the best design concept that meets the design requirements. Three iterations were performed by reducing the thickness of the original buckets, which was $2.96 \mathrm{~mm}$. The thickness of buckets used for iterations I, II and III were 1.5, 1.2 and $1.2 \mathrm{~mm}$, respectively, and they were all in the safe region. The corresponding weights were $2.34,1.88$ and 1.88 , respectively. The authors concluded that using a bucket thickness of $1.2 \mathrm{~mm}$ showed positive results with the stress and deflection in a permissible range and this resulted in a weight reduction of $36 \%$.

In their paper, Shinde et. al. [12] performed a material optimization and modal analyses using the FEA. The main goal of this paper was to obtain a new material that meets the strength requirements of a bucket of a bucket elevator and to predict the response of the buckets to a resonance under any external force. 


\begin{tabular}{|c|c|c|c|}
\hline Output Capacity/t/hr & Max. Deflection/mm & Max. Stress/MPa & Factor of safety \\
\hline 10 & 0.08 & 226 & 1.16 \\
\hline 15 & 0.07 & 233.9 & 1.068 \\
\hline 20 & 0.08 & 247.9 & 1.008 \\
\hline
\end{tabular}

TABLE 3. Gear Shaft Assembly Simulation Result.

\begin{tabular}{lccc}
\hline Output Capacity/t/hr & Max. Deflection/mm & Max. Stress/MPa & Factor of safety \\
\hline 10 & 3.104 & 230.444 & 1.084 \\
15 & 4.541 & 116.583 & 2.14 \\
20 & 5.906 & 153.251 & 1.6 \\
\hline
\end{tabular}

TABLE 4. Gear Shaft Assembly Simulation Result.

The bucket was modelled using CAD, meshing was done using HYPERMESH and, finally, ANSYS was used to perform the static and modal analyses. It was concluded that the design was safe since the stress and deformation values were below the critical values.

In their study, Pérez-Aparicio et. al [13] employed the Discontinuous Deformation Analysis (DDA) to analyse the bucket elevator discharge of granular materials for several velocities, bulk materials and bucket shapes. The results were in good agreement with existing analytical and experimental results. The behaviour of granular materials inside and outside of the most common bucket types was determined using a parametric analysis. It was concluded that the most efficient shape of the bucket for any specific working conditions can be designed using the analyses presented.

In their paper, Chavhan et. al. [14] modelled and subsequently performed the Finite Element Analysis of an elevator bucket. The authors considered two buckets, one made of steel and the other one of epoxy. Static structural analyses were performed using ANSYS and validated experimentally using universal testing machine (UTM). The weights of steel and epoxy buckets were $624 \mathrm{~g}$ and $147 \mathrm{~g}$, respectively, and resulted in a $76.4 \%$ decrement. Also, the maximum load carrying capacity of steel and epoxy buckets were $10 \mathrm{~kg}$ and $6 \mathrm{~kg}$, respectively, hence, the designed bucket was safe.

Rademacher [15] studied the non-spill discharge characteristics of bucket elevators and developed a non-spill theory for a simplified two-pulley model of a vertical bucket elevator with cylindrical buckets conveying a (very) cohesive material. The theory allows for an interrelated analysis and optimization of wheel radius, bucket height, bucket width, bucket spacing, wall friction coefficient inside the buckets, pulley speed, capacity, boundaries of the discharging flow of conveyed material, optimum - position of the chute and dimensioning of the casing head. In conclusion, a spill-free combination of the relevant parameters was found.
Haris [16] investigated the causes of a failure of a chain system through a characterization of the failed component. The analysis revealed that the weld defects such as craters lead to a crack propagation and a cyclic loading causes the fatigue failure. The fatigue failure occurred due to this inherited crack at the outer circumference of the weld within the chain attachment and outer chain link plate. This type of defect can also be categorized as a manufacturing defect. The fatigue crack propagation was evident by progressive beach marks, and the scanning electron microscopy (SEM) analysis revealed the types of microstructures that resulted at the heat affected zone (HAZ). Hardness testing using the Rockwell Tester found the different hardness profiles at the three areas, i.e., weld metal, base metal and heat affected zone. The maximum hardness values were found at the heat affected zone and the weld metal. Cracks generated at the outer circumference of the weld within the chain attachment and outer chain links' plate within the material led to the fatigue failure. Haris proposed that the thickness of the outer link should be increased, but did not study how this increase will impact the weld strength or weld defects (craters) within the chain link.

In their study, using a visual examination, Sujata et. al [17 found a shallow crack on the surface of the chain link under a stereo-binocular microscope. The authors found that the fracture surface showed coarse crystalline features. The sample containing the crack was cut, mounted, metallographically prepared and observed under an optical microscope. The visual examination revealed a crack-like surface defect and the optical micrograph showed an oxide entrapment in the material near the surface. The authors used Energy Dispersive X-Ray (EDX) analysis in the SEM for the investigation and found that the non-metallic inclusions between the crack surfaces, were mainly iron oxide. The authors concluded that the conveyor chain links had failed due to the presence of manufacturingin defects. The defects were identified as forging laps or folds and can be summarized as inherent defects. The investigation also showed that surface defects were present in the billet itself. They then recommended 
that the billet should be properly dressed, and the surface defects should be removed prior to the forging operations. The significance of the coarse crystalline features and the iron oxide inclusions were not stated in this paper.

Bošnjak et. al. [18] carried out a failure investigation of the bucket wheel excavator crawler chain link to diagnose the cause of the damage. To identify the reasons behind the chain link failures, stress state calculations were performed as well as experimental investigations, which included visual and metallographic examinations, chemical composition analysis and tests of mechanical properties. The sulphur content obtained from the chemical analysis of both samples was higher, as compared with the specifications. This resulted in a decreased impact toughness, particularly under impact conditions. The significant decrease of elongation compared with the specified values confirmed the presumptions based on the results of the chemical composition. The obtained low values of elongation and contraction meant that the samples had a very low resistance to crack initiation and crack propagation. Based on the results of the numerical-experimental analyses, it was concluded that the chain link breakdowns are caused by 'manufacturingin' defects. The carbon content obtained from the chemical analysis was lower than that of the required standard, but the paper never considered this observation.

Yin et. al. 7] carried out a failure analysis of bucket elevator conveyor chain links using a visual examination, chemical analysis, and metallographic analysis. These processes were performed on both failed and functioning conveyor chain link samples. The carried out visual examination revealed that the failure was brittle fracture, because there was no necking. In addition, the researchers observed an offset between the sprockets evidenced by indentations on the outer link of the chain link as well as vibrations within the bucket elevator system. A chemical analysis performed on 5 samples established that Silicon (Si), Phosphorus (P), Sulphur (S), Manganese (Mn), Chromium (Cr) and Molybdenum (Mo) all met the British standard EN 10293 requirements for steel casting for engineering use but Carbon (C) did not. It was concluded that the failure was brittle fracture induced by inclusions, which were the root cause of failure of the conveyor chain links.

\subsection{SUMmARY}

From the reviewed papers, it can be seen that an extensive amount of work has been done on optimization of the bucket elevator by focusing on weight reduction of various components of the bucket elevator. The FEM is seen as an important tool in the optimization process and is less expensive, compared to an experimental approach. The failure of a bucket elevator chain link is inevitable as shown in literature published by [7, 16, 18. The main cause of the failure was all determined to be manufacturing defects (holes and inclusions), which generate micro-cracks. These microcracks propagate until a fracture occurs. Although other parts such as bearing, shaft, and gears can also fail, they do not fail as frequently as chain links. The failure of chain links does not reduce only productivity but also increases the cost of maintenance because of damaged buckets and links associated with the failure. This paper mainly delves into how the design can be improved to minimize down-time and eliminate damaging the bucket and chain links during a failure of a chain link.

\section{Design optimization AND OPERATION}

The proposed design incorporates a ratchet mechanism, which restricts the chains with the buckets mounted on it to move only in the clockwise direction. The chains never fail when the buckets are empty, but fail when they are filled with cement. When the chain fails, it descends to the bottom because of the force of gravity. While descending to the bottom, the motion of the chain tends to be in the counter clockwise direction, thus, the incorporated ratchet mechanism restricts the chain to move only in the clockwise direction and the chain is held in position and is prevented from dropping to the bottom of the elevator. The proposed design is shown in Fig. 5.

\subsection{Components of the Ratchet MECHANISM}

The main function of the ratchet mechanism is to ensure that the chain is prevented from dropping to the bottom when there is a failure. The ratchet is made up of toothed wheel (sprocket), a pawl/lever, and a spring. A break out section of the ratchet mechanism is shown in Fig. 6

The toothed wheel in this case is a spur gear and it is the rotating member of the mechanism. The prime mover, which is the motor, drives the chain and because the chain is in contact with the toothed wheel (spur gear), it rotates along with the chain. A lever is hinged/pivoted at one end and the other end is shaped to fit into a notch of the ratchet wheel to allow for clockwise motion and prevent counter-clockwise motion. A spring is incorporated to hold the pawl against the teeth to ensure that the pawl is in position all the time to perform its function effectively. Since the ratchet mechanism is going to be incorporated into an existing bucket elevator, the sprocket, chain and shaft will be the same as that of the existing bucket elevator.

\section{Methodology}

In this study, an analytical method was employed to determine the dimensions of each component of the incorporated ratchet mechanism and verified with the FEM (ANSYS). An analytical method was used 


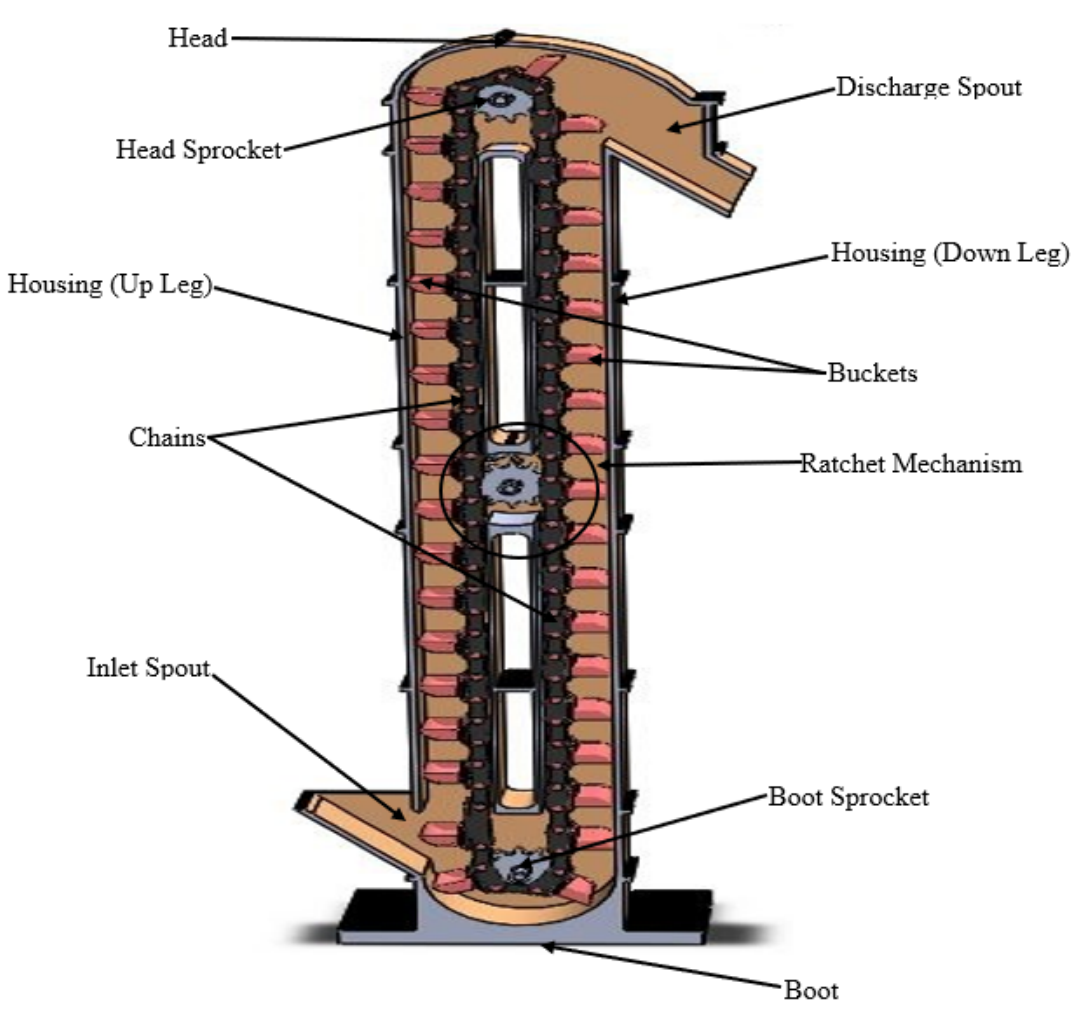

Figure 5. Designed bucket elevator.

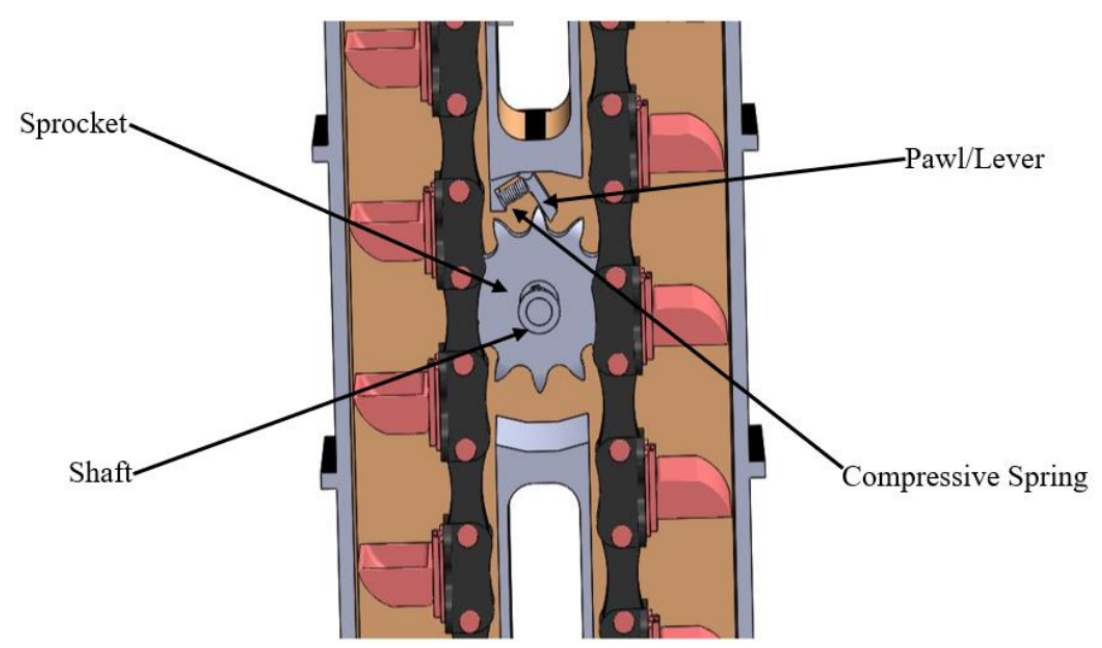

FiguRE 6. Ratchet mechanism. 


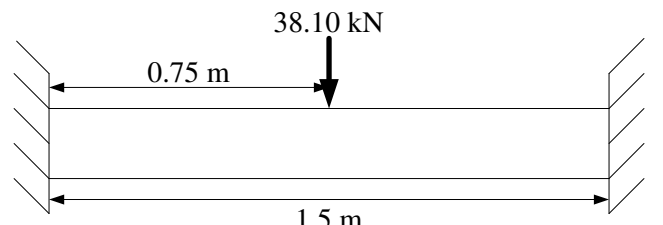

FiguRE 7 . Free body diagram of beam.

to obtain the maximum force and, subsequently, the diameter of the beam. The spring as well as the pawl/lever were also designed according to the force and the results were validated using ANSYS simulation software. Table 6 shows the various dimensions of the various parts of the ratchet mechanism.

\subsection{Design CALCUlation}

The design calculations involve calculations on the design of the beam, pawl and spring.

\subsubsection{Design of the BeAm}

The beam is the horizontal member on which the pawl will be mounted. It has a fixed support as shown in Fig. 7

The data collected from the plant on the existing bucket elevator.

- The length of the bucket elevator $=1.5 \mathrm{~m}$

- The weight of a bucket fully loaded with cement $=36 \mathrm{~kg}$

- The mass of a chain link per unit length $=88 \mathrm{~kg} / \mathrm{m}$

- The height of the bucket elevator $=30 \mathrm{~m}$

- For structural steel, the yield strength is $250 \mathrm{MPa}$

- The length of the elevator should be equal to the length of the bucket elevator for an easy assembly.

- The length of the beam is also $=1.5 \mathrm{~m}$

- One bucket, fully loaded with cement, weighs $36 \mathrm{~kg}$

- The chains always fail within the range of $15 \mathrm{~m}$ to $25 \mathrm{~m}$, the average between these two heights is $20 \mathrm{~m}$

- The number of buckets at a height of $20 \mathrm{~m}=59$ buckets

- For 59 buckets, the Mass $=36 \mathrm{~kg} \times 59=2124 \mathrm{~kg}$

- The mass per unit length of chain $=88 \mathrm{~kg} / \mathrm{m}$

- Since the average height is $20 \mathrm{~m}$, Mass of chain $=88 \times 20=1760 \mathrm{~kg}$

- The total mass $=$ mass of chain + mass of buckets $=1760+2124=3884 \mathrm{~kg}$

- Total weight, $W_{T}=m g=3864 \times 9.81=38.10 \mathrm{kN}$

The free body diagram of the beam is shown in Fig. 8

The Shear Force and Bending Moment diagram are shown in Fig. 9 .

From Fig. 9, it can be seen that the maximum Shear Force $(V)$ and Bending Moment $(M)$ are $18.95 \mathrm{kN}$ and $7.14 \mathrm{kN}$, respectively.

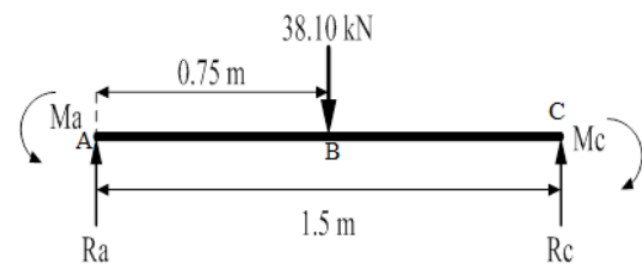

Figure 8. Free body diagram.

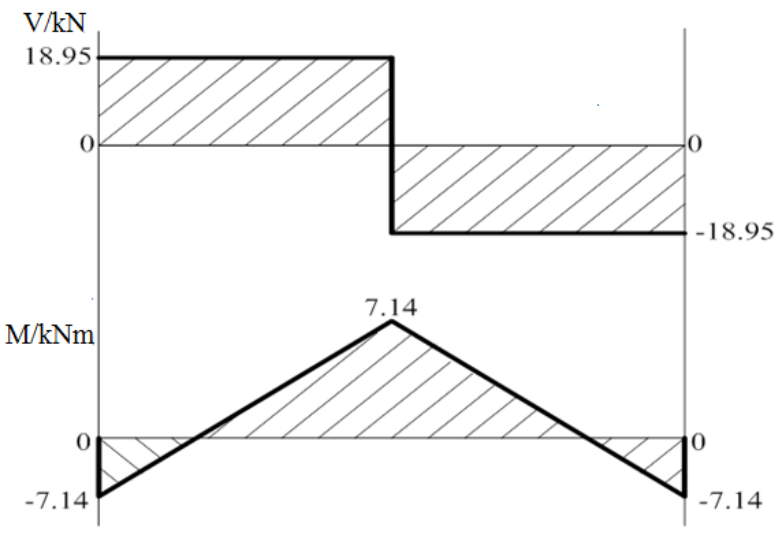

FiguRE 9. Shear force and bending moment diagram.

The beam is subjected to two main types of stresses:

- Bending stress

- Shear stress

From [18, the maximum bending and shear stress of a cylindrical beam is given in equations (4) and (5),

$$
\sigma_{b}=\frac{32 M}{\pi d^{3}}=\frac{32 \cdot 7.14}{\pi d^{3}}=\frac{72727.443}{d^{3}}
$$

The maximum shear stress is also given by:

$$
\tau_{\max }=\frac{16 V}{3 \pi d^{2}}=\frac{16 \cdot 18.95}{3 \pi d^{2}}=\frac{32170.519}{d^{2}}
$$

Using the distortion energy theory [18, the Von Mises Stress, $\nabla$ is given by;

$$
\nabla=\left(\frac{S_{y}}{n}\right)
$$

where $S_{y}=$ Yield strength, $n=$ Factor of safety.

Also, the Von Mises Stress [18], $\nabla$ is given by;

$$
\nabla=\left\{\sigma_{b}^{2}+3 \tau_{\max }^{2}\right\}^{0.5}
$$

Equating equations (6) and (7) gives,

$$
\begin{gathered}
\left(\frac{S_{y}}{n}\right)=\left\{\left(72727.443 / d^{3}\right)^{2}+3\left(32170.519 / d^{2}\right)^{2}\right\}^{0.5} \\
\left(\frac{S_{y}}{n}\right)=5289280965 / d^{6}+3104826878 / d^{4}
\end{gathered}
$$

Dividing through by $3104826878 d^{6}$ gives,

$$
\frac{d^{6}}{3.105 \times 10^{9}}\left(\frac{S_{y}}{n}\right)^{2}=1.704+d^{2}
$$




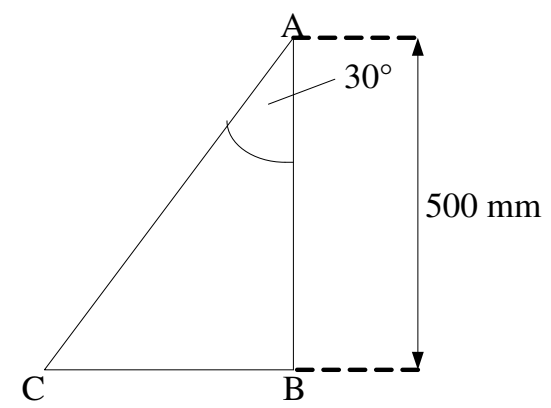

Figure 10. FBD for ratchet mechanism.

$$
\begin{gathered}
3.221 \times 10^{-10} d^{6}\left(\frac{S_{y}}{n}\right)^{2}=1.704+d^{2} \\
d^{2}\left\{3.221 \times 10^{-10} d^{4}\left(\frac{S_{y}}{n}\right)^{2}-1\right\}=1.704
\end{gathered}
$$

Either $d^{2}=1.704$ or $\left\{3.221 \times 10^{-10} d^{4}\left(\frac{S_{y}}{n}\right)^{2}-1\right\}=$ 1.704. When,

$$
\begin{gathered}
d^{2}=1.704 \\
\Longrightarrow d= \pm 1.305 \mathrm{~m}
\end{gathered}
$$

When,

$$
\left\{3.221 \times 10^{-10} d^{4}\left(\frac{S_{y}}{n}\right)^{2}-1\right\}=1.704
$$

using Structural steel, $S_{y}=250 \mathrm{MPa}$, and a factor of safety of 5 ,

$$
d= \pm \sqrt[4]{\frac{2.704}{3.221 \times 10^{-10}\left(\frac{250 \times 10^{6}}{5}\right)^{2}}}= \pm 42.81 \mathrm{~mm}
$$

From the two diameters calculated, the diameter of the beam is $43 \mathrm{~mm}$, because $1.305 \mathrm{~m}$ is too large.

\subsubsection{Design OF PAWL}

- The pawl is the member that fits into the notch of the sprocket to lock it.

- The pawl is of a rectangular shape and, from the collected data:

- The face width of the sprocket $=65 \mathrm{~mm}$

- The tooth thickness of the sprocket $=60 \mathrm{~mm}$

- Since the pawl is to fit into the notch of the sprocket, the width of pawl should be equal to the face width of the sprocket teeth. The width of the pawl $=$ $65 \mathrm{~mm}$

- Also, the height of the pawl should be equal to the tooth thickness of the sprocket teeth. The height of the pawl $=60 \mathrm{~mm}$

From the proposed design, Fig. 10 can be deduced, and therefore the length of the pawl, AC, can be calculated.

From Fig. 10. The length of the pawl $A C=$ $500 \sin 30^{\circ}=577 \mathrm{~mm}$. Since the force acting on the pawl is $38.10 \mathrm{kN}$ and it is a compressive force, the compressive stress is given by

$$
\nabla_{c}=-\frac{F}{A}=-\frac{38.1}{0.577 \times 0.065}=-1.015 \mathrm{MPa}
$$

From the Euler formula, the critical load for a member fixed at one end and free at the other end is given by

$$
\begin{array}{r}
P_{c}=\frac{\pi^{2} E I}{4 L^{2}}=\frac{\pi^{2} \cdot 210 \cdot 10^{9} \cdot 0.05 \cdot 0.06^{3}}{4 \cdot 12 \cdot 0.577^{2}}= \\
=-40.07 \mathrm{kN}
\end{array}
$$

Therefore, the critical compressive stress is given by

$$
\nabla_{c r}=\frac{140.07}{0.577 \cdot 0.05}=-4.855 \mathrm{MPa}
$$

Since $\nabla_{c}<\nabla_{c r}$, the pawl will not fail when it is being compressed by $38.10 \mathrm{kN}$ force. Therefore, the dimensions for the pawl are, $L=577 \mathrm{~mm}, W=50 \mathrm{~mm}$ and $H=60 \mathrm{~mm}$.

\subsubsection{Design OF SPRING}

In the design of the spring, because of space considerations, the total number of turns and the overall length of the spring are specified. The total number of turns $N_{t}$ and overall length $L_{o}$ are 10 turns and $537 \mathrm{~mm}$, respectively. Also, the type of the end of the spring is squared and ground because it has a good transfer of loads [18. The diameter of the spring wire is set to $25 \mathrm{~mm}$ so that the spring can withstand the load acting on it.

From Table 5 .

$$
N_{t}=N_{a}+2
$$

Number of active turns,

$$
N_{a}=N_{t}-2=8 \text { turns }
$$

From Table 5, Solid Length,

$$
L_{s}=d N_{t}=25 \cdot 10=250 \mathrm{~mm}
$$

From Table 5, Pitch

$$
P=\frac{L_{o}-2 d}{N_{a}}=\frac{537-2 \cdot 25}{8}=60.87
$$

From [18], the deflection of the spring is calculated using equation 13 ,

$$
\begin{aligned}
L_{o}=\operatorname{deflection}(y)+L_{s} \\
\Longrightarrow y=537-250=287 \mathrm{~mm}
\end{aligned}
$$

For the stability of the spring,

$$
\begin{aligned}
L_{o}=\leq 5.26 D & \\
\Longrightarrow & L_{o} \leq 5.26 \cdot 110 \leq 578.86 \mathrm{~mm}
\end{aligned}
$$

Since $L_{o}(537)<578.86 \mathrm{~mm}$, it implies that the spring is stable

$$
\text { Outside diameter, } \begin{aligned}
O D & =D+d= \\
& =110+25=135 \mathrm{~mm}
\end{aligned}
$$

Inside diameter, $I D=D-d=$

$$
=110-25=85 \mathrm{~mm}
$$




\begin{tabular}{lcccc}
\hline & \multicolumn{4}{c}{ Type of spring ends } \\
\cline { 2 - 5 } Term & Plain & Plain and ground & Squared or closed & Squared and ground \\
\hline End coils $N_{e}$ & 0 & 1 & 2 & 2 \\
Total coils $N_{t}$ & $N_{a}$ & $N_{a}+1$ & $N_{a}+2$ & $N_{a}+2$ \\
Free length $L_{o}$ & $p N_{a}+d$ & $p\left(N_{a}+1\right)$ & $p N_{a}+3 d$ & $p N_{a}+2 d$ \\
Solid length $L_{s}$ & $d\left(N_{t}+1\right)$ & $d N_{t}$ & $d\left(N_{t}+1\right)$ & $d N_{t}$ \\
Pitch $P$ & $\left(L_{o}-d\right) / N_{a}$ & $L_{o} /\left(N_{a}+1\right)$ & $\left(L_{o}-3 d\right) / N_{a}$ & $\left(L_{o}-2 d\right) / N_{a}$ \\
\hline
\end{tabular}

TABle 5. Formulas for the Dimensional Characteristics of Compression Spring $\left(N_{a}=\right.$ Number of active coil $)$ 18.

\begin{tabular}{ll}
\hline Part & Dimensions \\
\hline \multirow{2}{*}{ Beam } & Length $-1.5 \mathrm{~m}$ \\
& Diameter $-43 \mathrm{~mm}$ \\
\hline \multirow{3}{*}{ Pawl/Lever } & Length $-577 \mathrm{~mm}$ \\
& Width $-50 \mathrm{~mm}$ \\
& Height $-60 \mathrm{~mm}$ \\
\hline \multirow{5}{*}{ Spring } & Total number of turns $N_{t}=10$ turns \\
& Overall length, $L_{o}=537 \mathrm{~mm}$ \\
& Diameter of spring wire, $D=25 \mathrm{~mm}$ \\
& Number of active turns, $N_{a}=8$ turns \\
& Solid Length, $L_{s}=250 \mathrm{~mm}$ \\
& Pitch $P=60.87$ \\
& Outside diameter, $O D=135 \mathrm{~mm}$ \\
& Inside diameter, $I D=85 \mathrm{~mm}$ \\
& $K=132.75 \mathrm{kN} / \mathrm{m}$ \\
\hline
\end{tabular}

TABle 6. Design parameters.

\subsection{Force ANALYSIS OF RATCHET MECHANISM}

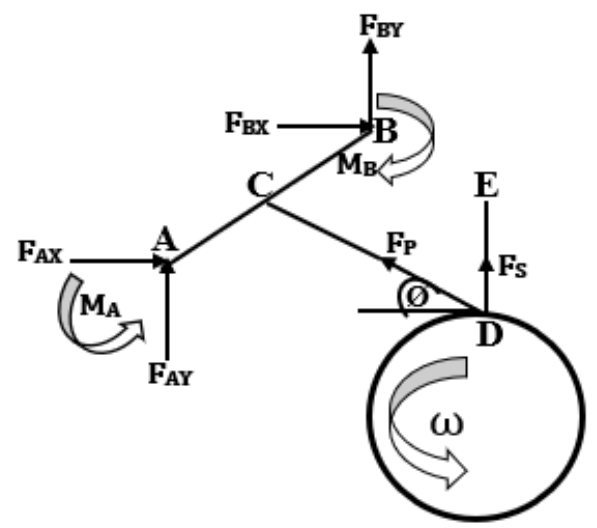

FiguRE 11. Force analysis of ratchet mechanism.

Member $A B$ is the Beam on which the lever is mounted. Member $D E$ is the spring that keeps the pawl in position, i.e., in the flute of the sprocket. $F_{S}$ is the force in the spring. $F_{P}$ is the force acting on the pawl. $F_{A X}$ and $F_{A Y}$ are the forces acting at the fixed end $A$ of the beam in the $X$ and $Y$ direction, respectively. $F_{B X}$ and $F_{B Y}$ are the forces acting at the fixed end $B$ of the beam in the $X$ and $Y$ direction, respectively. $M_{A}$ and $M_{B}$ are the moments acting at points $A$ and $B$ of the beam. The force that will act on the pawl is $38.10 \mathrm{kN}$, since this is the weight that the pawl must withstand when there is a failure of any of the chain links. The force that will act on the spring will be the torque transmitted by the sprocket onto the pawl during the operation. This force was calculated as:

$$
P=F_{s} v_{s}
$$

where

$P$ - Motor Power

$F_{s}$ - Force on the Spring

$V_{s}$ - Linear velocity of the Sprocket

Also,

$$
F_{s}=\frac{P}{v_{s}}=\frac{57}{1.62}=35.18 \mathrm{~kW}
$$

CAD models were designed using the Autodesk Inventor student software, and the simulation was done using the ANSYS academic software. Fig. 12 is a flow chart showing the procedure for the stress analysis and topology optimization.

\subsection{Kinematic Analysis of Ratchet MECHANISM}

The kinematic diagram of the ratchet mechanism is shown in Fig 13

From the kinematic diagram shown in Fig. 13 the displacement of the Pawl/Lever $X$ is given by:

$$
X=L \cdot \sin \varnothing \quad 0 \leq \varnothing \leq 30^{\circ}
$$




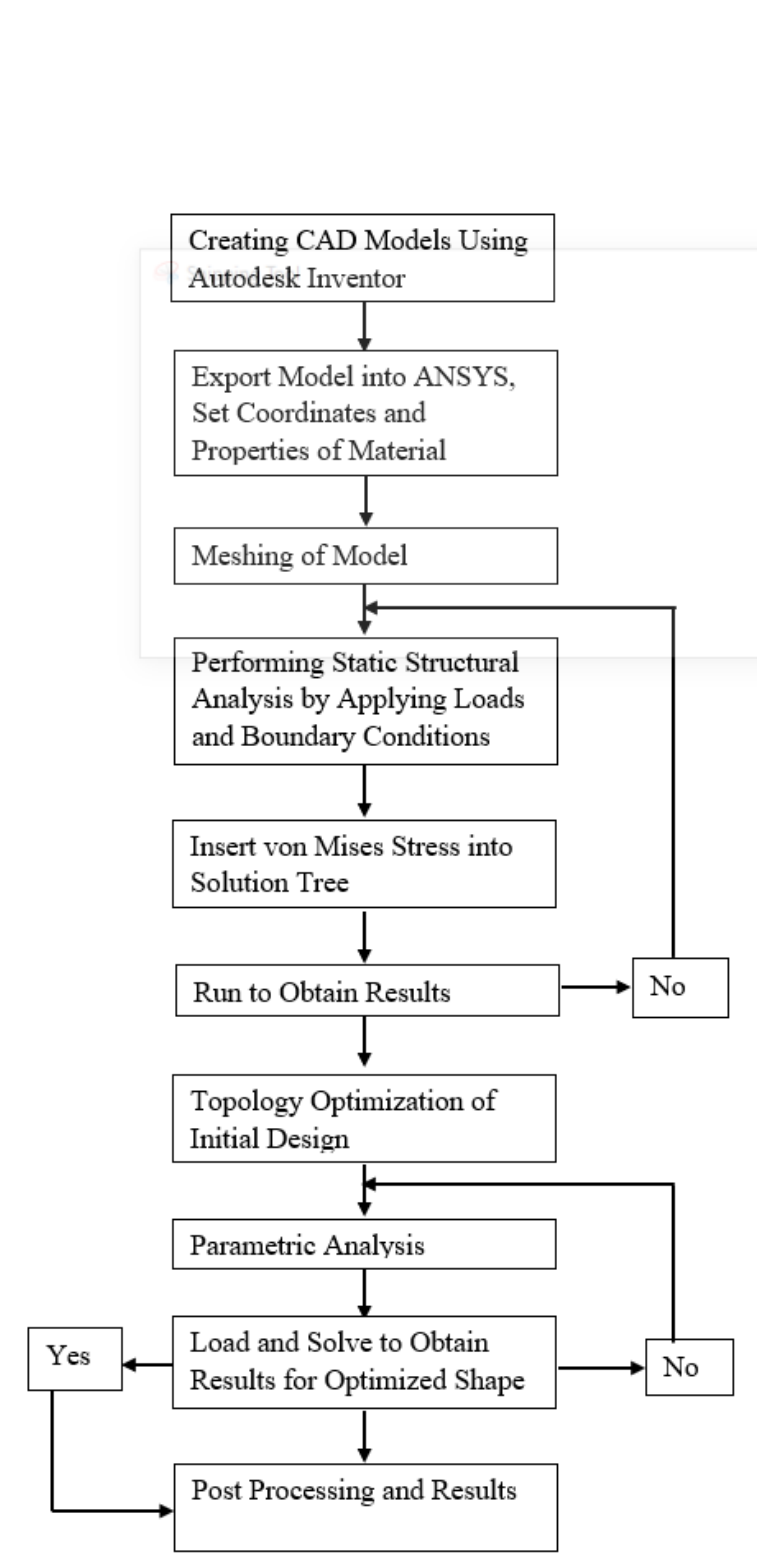

Figure 12. Flow chart for FEM analysis.

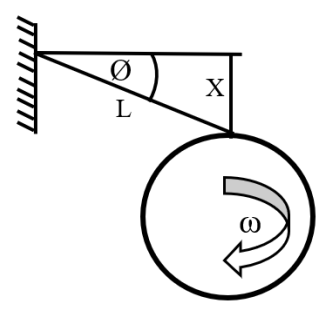

FiguRE 13. Kinematic diagram. where

$X$ is the Displacement

$L$ is the length of pawl/lever

$\varnothing$ is the angle subtended by the pawl and the $x$-axis The velocity of the Pawl/Lever is given by:

$$
\dot{X}=\frac{d X}{d t}=\frac{d X}{d \varnothing} \times \frac{d \varnothing}{d t}
$$

but

$$
\frac{d \varnothing}{d t}=\omega
$$

Putting eqn 21 into eqn 20 gives,

$$
\dot{X}=\omega \frac{d X}{d \varnothing}
$$

From eqn (19),

$$
\frac{d X}{d \varnothing}=L \cos \varnothing
$$

Putting eqn 23 into eqn 22 gives,

$$
\dot{X}=\omega L \cos \varnothing \quad 0 \leq \varnothing \leq 30^{\circ}
$$

The acceleration of the pawl/lever is given by:

$$
\ddot{X}=\frac{d \dot{X}}{d t}=\frac{d \dot{X}}{d \varnothing} \times \frac{d \varnothing}{d t}
$$

From eqn $21, \frac{d \varnothing}{d t}=\omega$

$$
\ddot{X}=\omega \frac{\dot{X}}{d \varnothing}
$$

From eqn 24,

$$
\frac{d \dot{X}}{d \varnothing}=-\omega L \sin \varnothing
$$

Putting eqn 27 into eqn 26 gives,

$$
\ddot{X}=-\omega^{2} L \sin \varnothing \quad 0 \leq \varnothing \leq 30^{\circ}
$$

\section{Results AND DISCUSSION}

\subsection{KinematiC ANALYSIS}

The kinematic analysis was carried out on the ratchet mechanism to determine the maximum displacement, velocity and acceleration. From equations (19, 24) and (28), the following graphs were plotted as shown in Fig. 14. The displacement was a function of the length and the angle subtended by the pawl whereas the velocity and acceleration were a function of length and the angle subtended by the pawl as well as the angular speed of the sprocket. These parameters influenced their respective maximum values occurring at different angular positions.

The maximum displacement was determined to be $0.2885 \mathrm{~m}$ as shown in Fig. 14a and occurred when the angle subtended between the pawl and the beam was $30^{\circ}$ or $0.5236 \mathrm{rad}$. From equation (1), it was deduced 


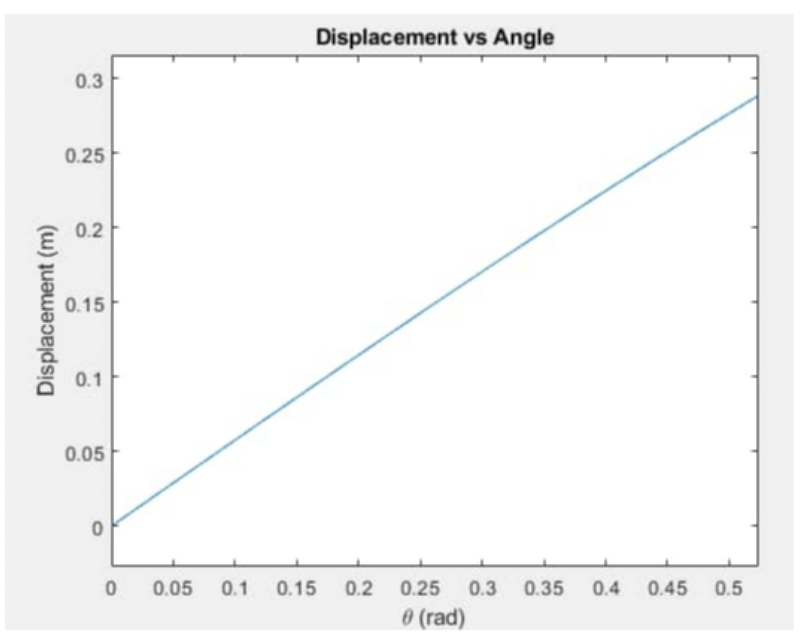

(A).

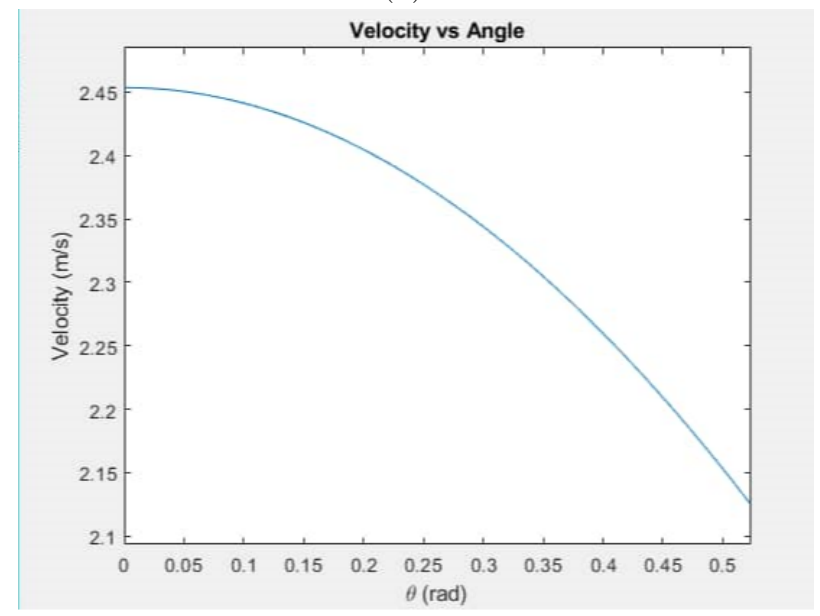

(в).

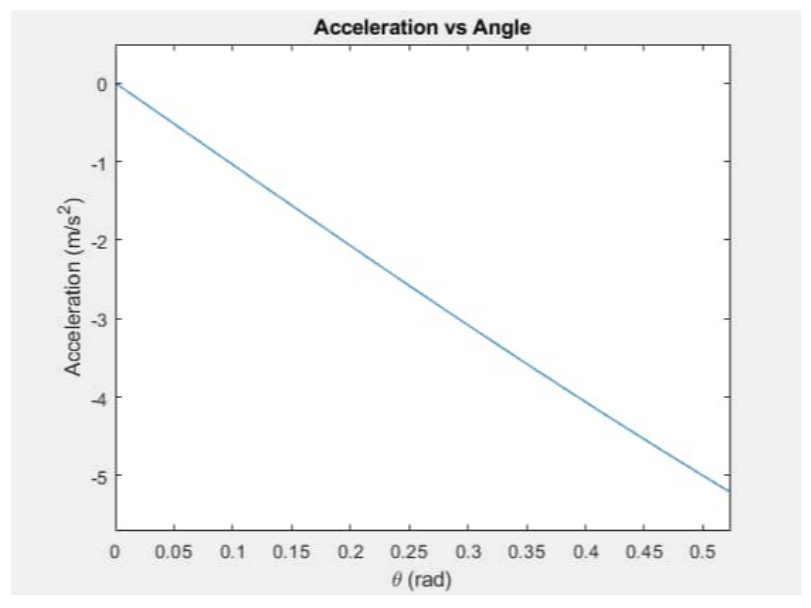

(C).

Figure 14. Force analysis of ratchet mechanism. that the maximum displacement was equal to the half-length of the pawl since $\sin 30^{\circ}$ equals to $1 / 2$.

The velocity reached a maximum when the angle subtended between the pawl and the beam was zero. The obtained value was $2.453 \mathrm{~m} / \mathrm{s}$ as shown in Fig. 14b which was equal to the product of the angular velocity and the length of the pawl since $\cos 0^{\circ}$ is unity.

The acceleration of the pawl was equal to half of the product of the length of the pawl and the square of the angular velocity since the $\sin$ of $30^{\circ}$ equals to $1 / 2$. The value obtained was $5.216 \mathrm{~m} / \mathrm{s}^{2}$ as shown in Fig. $14 \mathrm{c}$

\subsection{Finite ELEMENT ANALYSIS}

The sizing of the pawl, spring and beam was done using analytical formulas to determine the dimensions of the parts. Subsequently, a static structural analysis of the parts was carried out to validate the results obtained analytically, using ANSYS academic. These results are presented in Fig. 15

The maximum von Mises stress acting on the beam, as shown in Fig. 15a, was $70.87 \mathrm{MPa}$ and occurred at the midspan of the beam where the force was applied. The material used was structural steel with a yield strength of $250 \mathrm{MPa}$, and therefore the design was safe since the maximum stress was less than the yield strength of the material. As a result, the maximum deformation will also be at the midspan with the factor of safety being more than unity (1).

For the pawl, the maximum von Mises stress, as shown in Fig. 15b occurred at the tip as the force was applied at that point. The obtained value of the stress was $82.75 \mathrm{MPa}$, which was lower that the yield strength of the structural steel (250 MPa). As a result, the maximum deformation will also be at the tip with the factor of safety being more than unity (1). Case hardening of the tip of the pawl is, therefore, recommended to prevent an excessive wear as the tip will be in a direct contact with the sprocket.

The maximum von Mises stress acting on the spring, as shown in Fig. 15c was $132.54 \mathrm{MPa}$ and it occurred at the inner fibre of the spring. The material used was structural steel with a yield strength of $250 \mathrm{MPa}$, and therefore the design was within the safe region. It was also noted that the spring had the highest stress acting on it, and therefore is the most critical part of the ratchet mechanism so it must be monitored regularly during a regular maintenance. As the spring would be subjected to pull-release cycles repeatedly, a fatigue analysis was performed to estimate the fatigue life of the spring. The fatigue life of the spring was estimated to be $1.16 \mathrm{e} 05$ as shown in Fig. $15 \mathrm{~d}$.

\subsection{TOPOLOGY OPTIMIZATION ANALYSIS}

The stress profile from the simulation of the beam and lever showed that there is a room for a topology optimization, so it was carried out using ANSYS academic simulation software and the results are shown in Fig. 16 and Fig. 17 

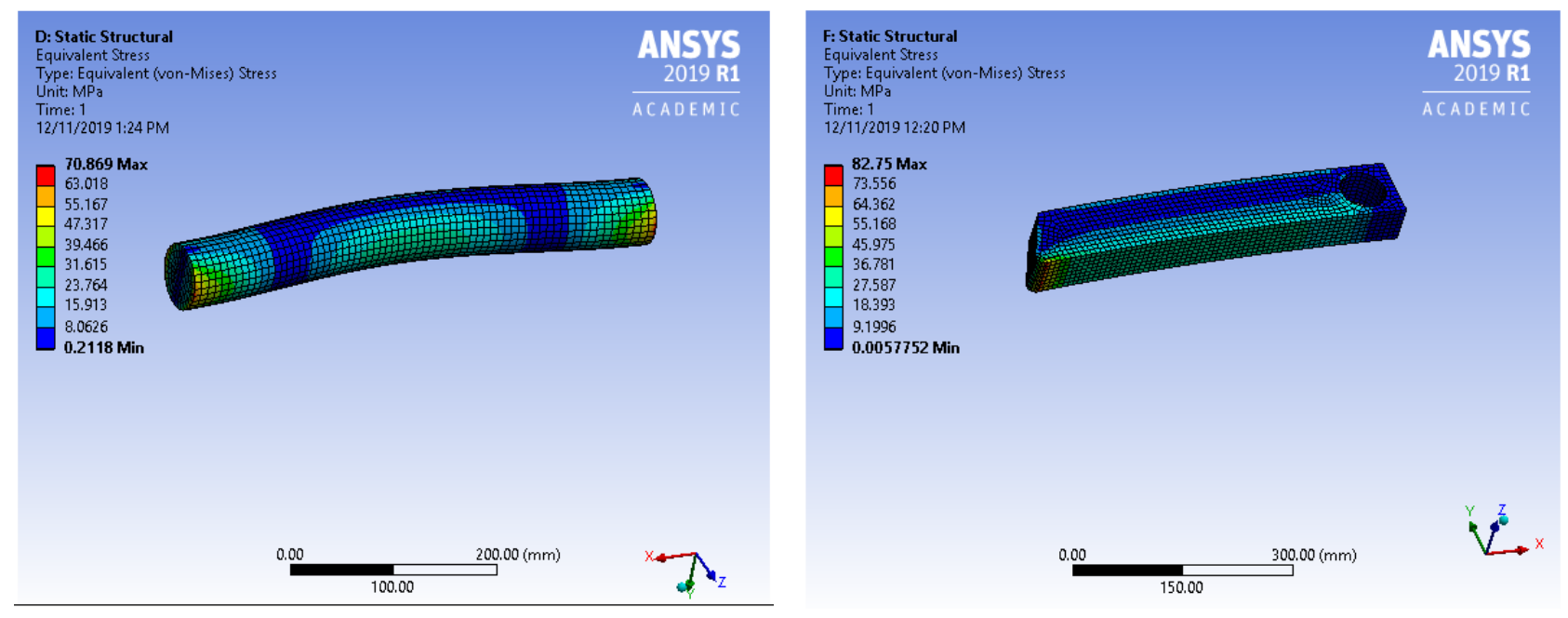

(A).

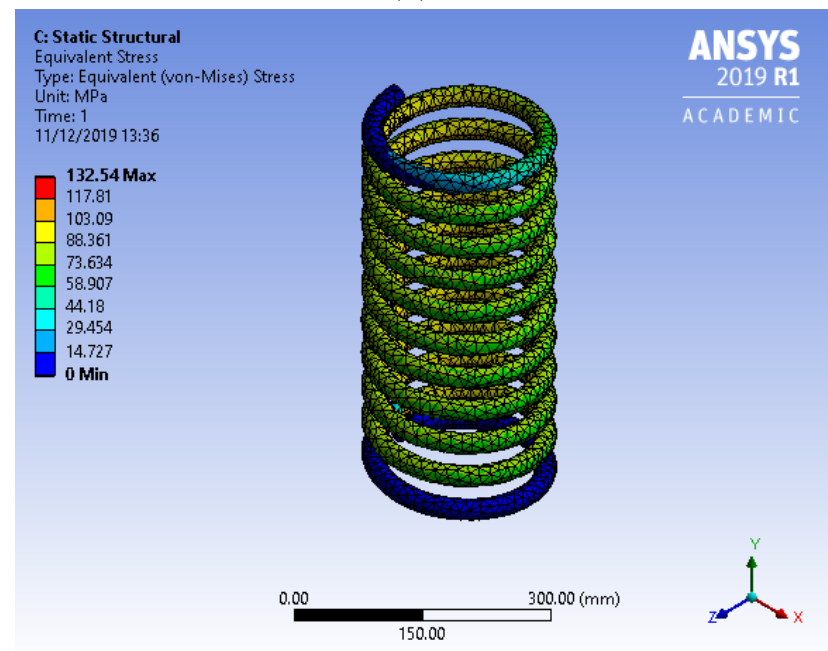

(B).
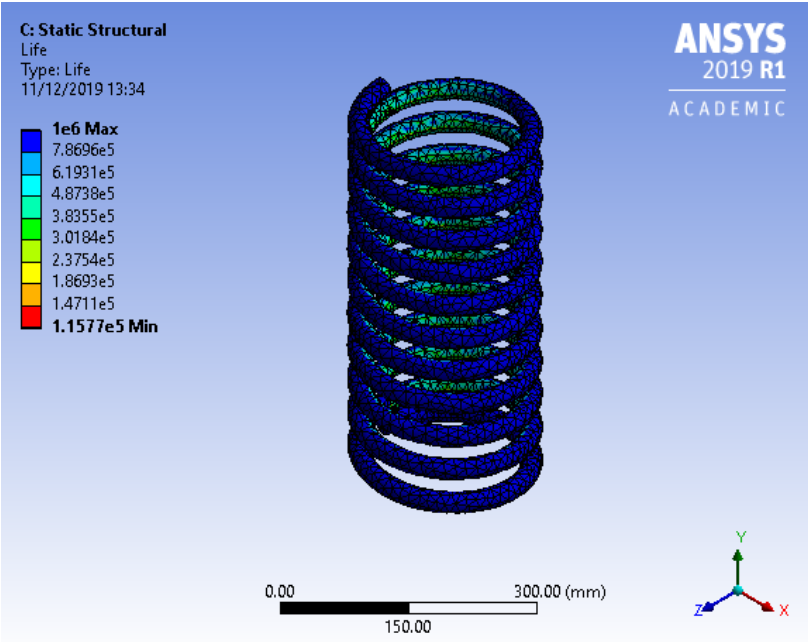

(c).

(D).

Figure 15. Static structural analysis.

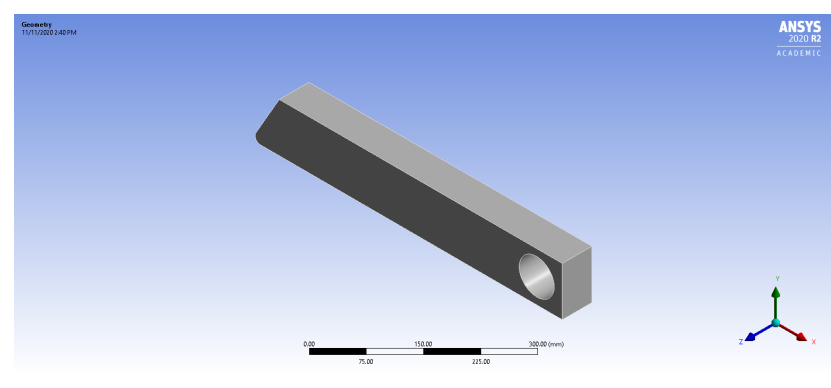

(A).

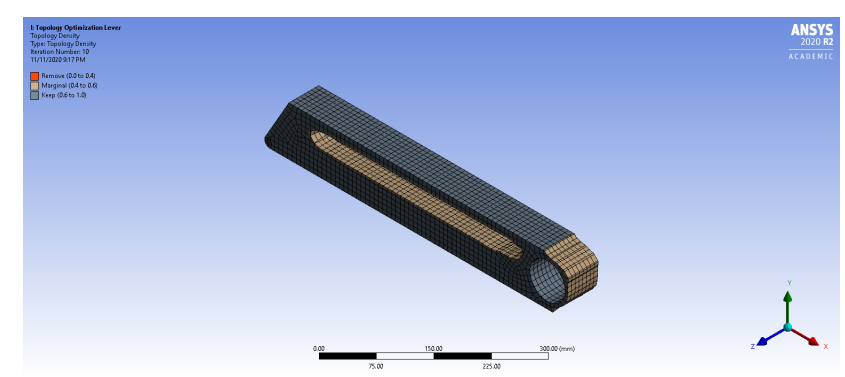

(в).
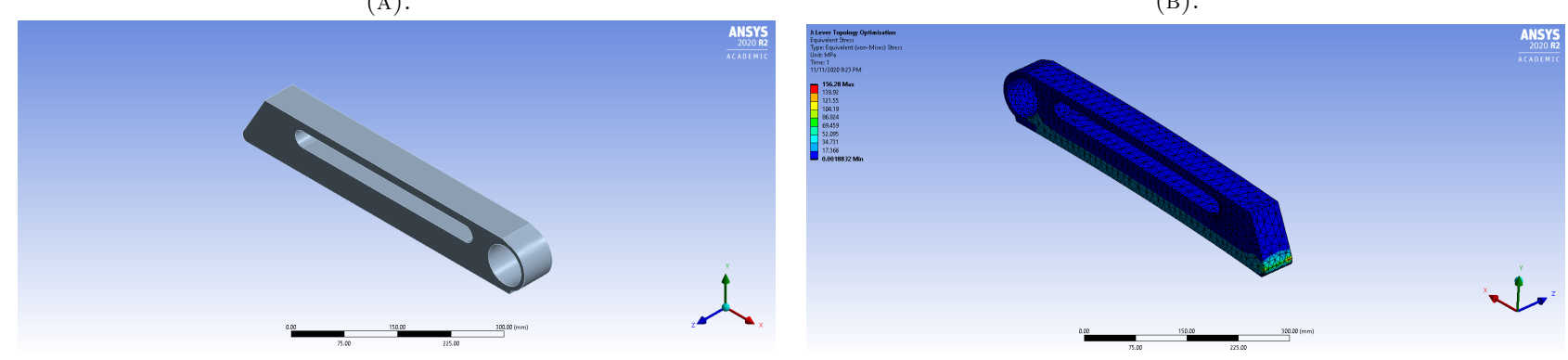

(C).

(D).

FiguRE 16. Lever topology optimization. 


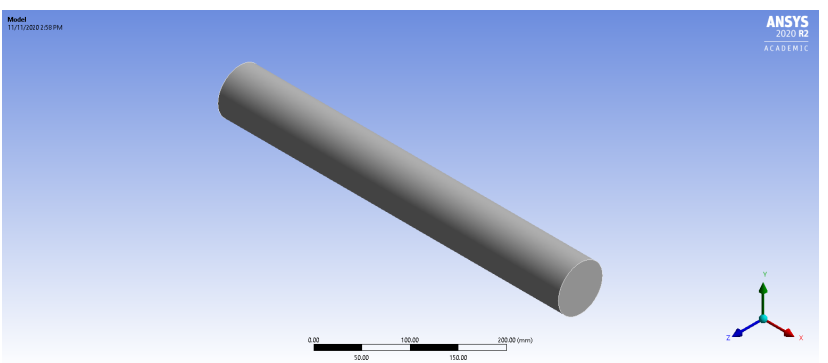

(A)

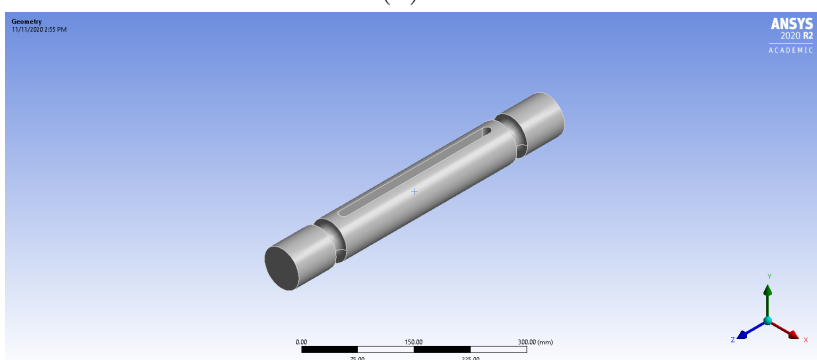

(c).

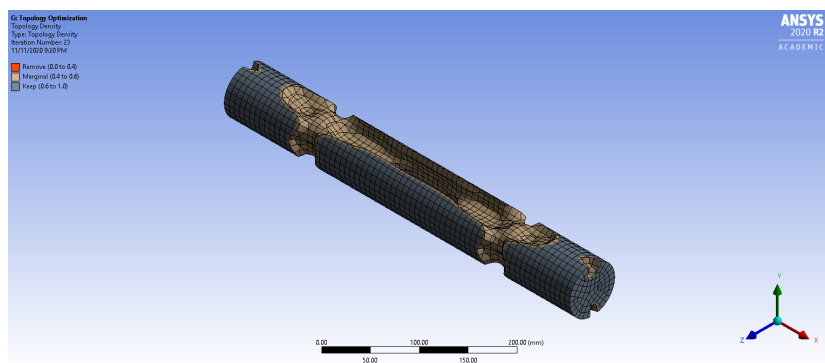

(B).

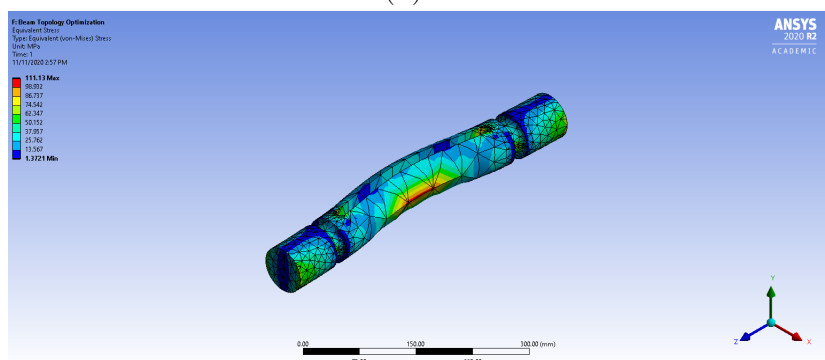

(D).

Figure 17. Beam topology optimization.

The topology optimization was carried out to obtain the best possible shape to reduce weight, thereby saving material. The original mass of the lever was reduced from $19.949 \mathrm{~kg}$ to $14.777 \mathrm{~kg}$ and the volume was reduced from $2.5413 \mathrm{~m}^{3}$ to $1.8824 \mathrm{~m}^{3}$. This resulted in a $26 \%$ reduction in mass and volume. Due to the mass and volume reduction, the von-Mises stress increased from $82.75 \mathrm{MPa}$ to $156.28 \mathrm{MPa}$ which was a $47 \%$ increment from the original stress value, but still being within the permissible limits.

The topology optimization was also carried out for the beam as well to obtain the best possible shape at the lowest cost. The original mass of the beam was reduced from $13.024 \mathrm{~kg}$ to $10.401 \mathrm{~kg}$ and the volume from $1.6592 \mathrm{~m}^{3}$ to $1.325 \mathrm{~m}^{3}$. This resulted in a $20 \%$ reduction in mass and volume. Due to the mass and volume reduction, the von-Mises stress increased from $70.869 \mathrm{MPa}$ to $111.13 \dot{\mathrm{MPa}}$, which was a $36 \%$ increment from the original stress value, but still being within the permissible limits.

The maximum stresses from the simulation occurred at the tip of the beam and at the midspan of the beam where the force was applied, and therefore a heat treatment should be carried out in that region to increase its strength.

\section{Conclusion}

The bucket elevator was modified by incorporating a ratchet mechanism for the purpose of preventing the bucket chain assembly from dropping to the bottom of the elevator when there is a chain failure, which is inevitable. An analytical method was used for the design and, subsequently, a static structural analysis of the various members of the mechanism was carried out using ANSYS with the stresses being within the permissible limits. The maximum von Mises stress acting on the beam was $70.87 \mathrm{MPa}$ and, after an optimization, it increased to $111.13 \mathrm{MPa}$. For the lever, the maximum von Mises stress was $82.75 \mathrm{MPa}$ and this value increased to $156.28 \mathrm{MPa}$ after an optimization. The maximum von Mises stress acting on the spring was $132.54 \mathrm{MPa}$. Although the stresses increased after the optimizations, it resulted in a $20 \%$ and $26 \%$ reduction in mass and volume of the beam and lever, respectively. A kinematic analysis of the mechanism was also performed and the displacement, velocity, and acceleration of the pawl were $0.2885 \mathrm{~m}$, $2.453 \mathrm{~m} / \mathrm{s}$ and $5.216 \mathrm{~m} / \mathrm{s}^{2}$, respectively. In conclusion, this mechanism will aid in reducing the down-time and maintenance costs, thereby increasing productivity. The adoption of this new design in the lime, cement, and grain industry as well as in the building industry will improve productivity.

\section{REFERENCES}

[1] J. S. Quincha Munoz. Engineering Optimization Showcase. bachelor, The University of Queensland, 2017.

[2] H. K. Kulkarni, R. J. Patil. Failure analysis and weight optimization of chain conveyor system. International Journal of Advanced Engineering Research and Studies 4(2):23 - 26, 2015.

[3] E. Yin, O. Muvengei, J. Kihiu, K. Njoroge. Failure analysis on conveyor chain links of a central bucket elevator. IOSR Journal of Mechanical and Civil Engineering 13(4):56 - 63, 2016. DOI:10.9790/1684-1304075663

[4] M. D. Jagtap, B. D. Gaikwad, P. M. Pawar. Study of roller conveyor chain strip under tensile loading. International Journal of Modern Engineering Research 4(5).

[5] K. Robinson. The voice of the north american conveyor industry. In Conveyor Equipment Manufacturers Association Engineering Conference. Florida, USA, 2012. 
[6] N. Yashaswini, B. Raju, A. Purushottham. Design and optimization of bucket elevator through finite element analysis. IPASJ International Journal of Mechanical Engineering 2(9):73 - 78, 2014.

[7] O. M. E. Yin, J. M. Kihiu, O. Muvengei. Metallographic failure analysis on bucket elevator conveyor chain links. Journal of Advancements in Material Engineering 4(3):27 - 40, 2019. DOI:10.5281/zenodo.3516549

[8] S. Patel, S. Patel, J. Patel. Productivity improvement of bucket elevator by modified design. International Journal of Emerging Technology and Advanced Engineering 3(1):128 - 133, 2013.

[9] G. A. Taher, Y. Howlader, M. A. Rabbi, F. A. Touqir. Automation of material handling with bucket elevator and belt conveyor. International Journal of Scientific and Research Publications 4(3):1 - 13, 2014.

[10] A. Barshi, K. Singh, O. Patil, S. Yadav. Design, analysis and optimization of bucket elevator.

International Journal of Advanced Engineering and Innovative Technology 1(1):85 - 89, 2019.

[11] S. P. Deokar, A. Lagad, S. S. Kelkar. FEA and Optimization of elevator bucket. International Engineering Research Journal pp. 975 - 980, 2015.

[12] S. T. Shinde, V. S. Dixit, M. R. Nukulwar, S. S. Pimpale. Material optimization and modal analysis of elevator bucket 6(2):574 - 580, 2016.
[13] J. L. Pérez-Aparicio, R. Bravo, J. J.

Gómez-Hernández. Optimal numerical design of bucket elevators using discontinuous deformation analysis.

Granular Matter 16(4):485 - 498, 2014. DOI:10.1007/s10035-014-0485-5.

[14] H. K. Chavhan, K. C. More, U. U. Patil. Design and analysis of bucket elevator. International Journal of Scientific and Technology Research 9(3):3296 - 3301, 2020 .

[15] F. J. C. Rademacher. Non-spill discharge characteristics of bucket elevators. Powder Technology 22(2):215 - 241, 1979. DOI:10.1016/0032-5910(79)80029-7

[16] N. I. B. Haris. Failure Analysis of Conveyor Chain Links: A Case Study at Top Glove Sdn. Bhd. Master's thesis, Universiti Tun Hussein Onn Malaysia, 2013.

[17] M. Sujata, M. A. Venkataswamy, M. A. Parameswara, S. K. Bhaumik. Failure analysis of conveyor chain links. Engineering Failure Analysis 13(6):914 - 924, 2006. DOI:10.1016/j.engfailanal.2005.07.002.

[18] R. Budynas, K. Nisbett. Shigley's Mechanical Engineering Design. McGraw-Hill, 9th edn., 2011. 